\author{
EVS29 Symposium \\ Montréal, Québec, Canada, June 19-22, 2016
}

\title{
Winning Approach: Selection Criteria for Competitive Battery Powered Racing Vehicles
}

\author{
Eva Håkansson ${ }^{1}$, Bill Dubé ${ }^{1}$, \\ ${ }^{1}$ KillaJoule-KillaCycle Racing Team, P.O. Box 1243, Wheat Ridge, CO, 80034, USA, \\ contact@evahakanssonracing.com,www.EvaHakanssonRacing.com
}

\begin{abstract}
Summary
This paper presents a systematic approach for optimal selection of race discipline and race format to develop a battery powered racing vehicle that is competitive with internal combustion vehicles.

The main limitation for battery powered vehicles is the mass of the battery that grows directly with race duration, and the break-even point is currently around 10 minutes. However, battery powered vehicles have other advantages such as indifference to altitude, superior traction control, and moldability of the drivetrain for aerodynamic advantage or for optimal weight distribution, making them highly competitive in certain disciplines such as land speed racing and hill climb.
\end{abstract}

Keywords: BEV, demonstration, off-road, promotion, vehicle performance

\section{Introduction}

Electric vehicles are going to be a game changer in motorsport due to their high power, instant torque, indifference to altitude, superior traction control, and moldability of the drivetrain for aerodynamic advantage or for optimal weight distribution. The main limitation for battery powered vehicles is the mass of the battery that grows directly with race duration. At the current technology level, battery powered racing vehicles can be top contenders in most races that don't exceed about 10 minutes. The 2015 victory by Rhys Millen in the Drive eO electric car in the legendary and incredibly challenging Pike's Peak International Hill Climb clearly demonstrates the potential. The battery powered KillaJoule being the world's fastest sidecar motorcycle also speaks for itself.

Racing is a great application to demonstrate the capabilities of electric drive and to change the general public's perception of energy efficient technology. It is also a great arena to showcase new battery technology and other drivetrain components. However, to get the maximum benefit from your racing effort, it is important to select a race discipline and race format where battery powered electric vehicles (EVs) can be competitive with internal combustion vehicles (ICEs).

This paper will present a systematic approach and criteria for an optimal selection of race discipline, format, and vehicle type in order to develop a battery powered racing vehicle that can compete head-tohead with ICE vehicles. It will also briefly cover budget, overall goals of the racing effort, sponsorship, and publicity strategy. 


\subsection{Assumptions}

This paper is based on the assumption that you want to race to be competitive, which we define as setting a record or place in the top half of the field. Many people have their hearts set for a specific vehicle or race, or just want to participate for the joy of it. If you are one of these, you may still find this paper useful, but you are not in the main target group. This paper is for the individuals and teams that want to showcase a certain component, or want to promote the capabilities of electric vehicles in general, or simply want to win. The purpose of our own racing effort, which will be covered in more detail below, is to showcase the capabilities of EVs. We call it "eco-activism in disguise". Our mission is to show that eco-friendly can be fast and fun, and hopefully make people that otherwise wouldn't be interested in low-emission vehicles be aware of their potential. Speed is a great way of showing the potential of battery power, because fast is always in fashion!

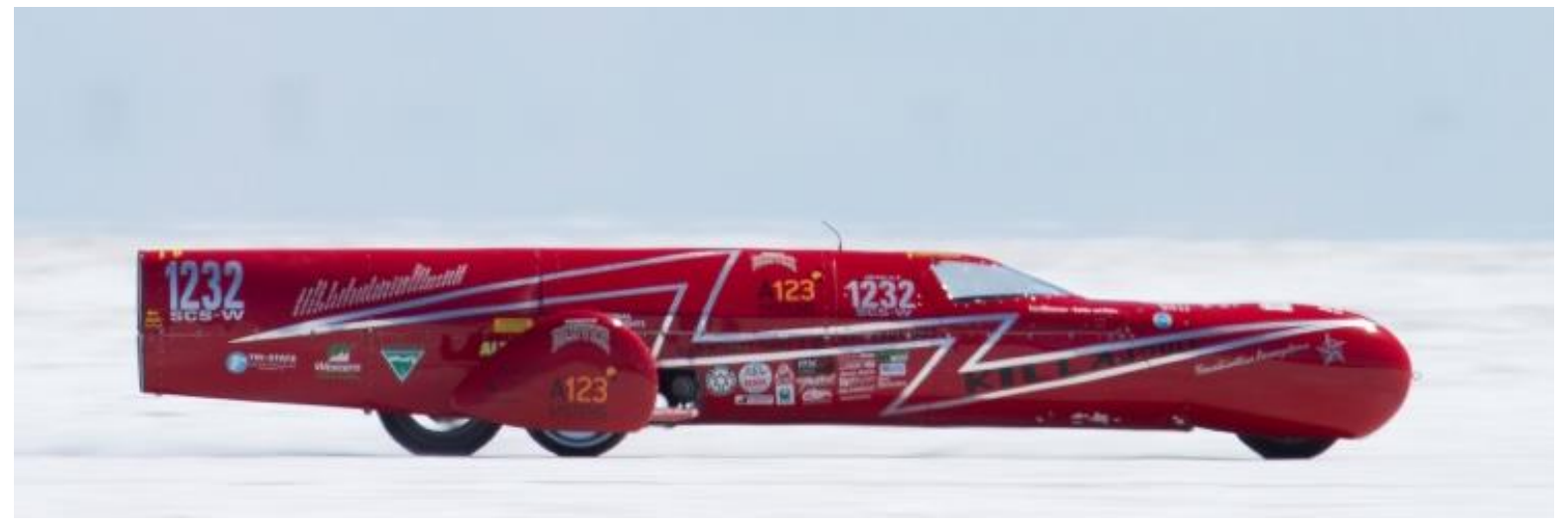

Figure 1: Land speed racing provides a perfect race format for battery powered vehicles. The battery powered KillaJoule, piloted by Eva Håkansson, is the world's fastest sidecar motorcycle. Photo courtesy of Scooter Grubb.

\section{Strength and weaknesses of battery powered vehicles}

In the process of selecting a suitable race discipline and vehicle type, the strength and weaknesses of EVs need to be considered. The list below summarizes the main strength and weaknesses of EVs in a race application. Some of them are obvious, while some are more subtle.

\section{Strengths}

- Very high power drivetrains available.

- Instant torque from zero rpm.

- $\quad$ Reduced driver workload $=$ the driver can focus on the track and the race.

- Greatly reduced number of moving parts = less wear of parts, higher reliability, less maintenance.

- Low maintenance $=$ small crew requirements.

- Silent drivetrain = allows driver to hear competitors, and can allow for track use during noise abatement hours or for use of locations otherwise not available for racing activities.

- No gain/loss of HP due to barometric pressure, humidity, or air temperature.

- No fuel starvation due to vehicle acceleration, turns, etc.

\section{Weaknesses}

- Limited run time per charge due to much lower specific energy in batteries compared to liquid fuels $=$ only competitive with ICE in race formats of short duration.

- Relatively long time required for recharge/battery swap compared to refueling an ICE.

- Novelty of components and systems = difficult to find experienced crew and suppliers.

- No local spare parts suppliers.

- Can be EMI/RFI issues with controls, instruments, radios, etc.

- Complex electronics.

- Spare battery pack shipping restrictions = logistics for racing at distant location can be complicated, slow, and expensive. 


\subsection{The current run-time limitation: approximately 10 minutes}

The main limitation for EVs in race applications is currently the limited run-time per charge. This is solely due to the low specific energy of batteries compared to liquid fuels. This forces the selection of a short duration race format. Some race disciplines such as land speed racing and hill climb have inherently short durations. Others such as traditional circuit racing come in many different formats, from short sprint races to 24 hour endurance races. In the latter case, we will show that battery power only can be competitive in the short race format with the current state-of-the-art battery technology.

In order to be competitive in circuit racing and similar competitions with frequent turning and braking, the mass of the EV needs to be similar to the mass of the ICE competitor. While some of the possible strengths of EVs such as better weight distribution, instant torque, and superior traction control might make up for a higher mass, the vehicle cannot be much heavier without sacrificing performance.

The current run-time limitation can be calculated by comparing the mass of the EV drivetrain including the battery with the mass of the ICE drivetrain including the fuel. A comparison for a Le Mans style car can be found in in figure 3. The data comes from the Drayson B12/69EV car, which during its lifetime has been fitted both with an internal combustion engine and an electric drivetrain. The Drayson B12/69EV (Figure 2) is a "Le Mans prototype type 1" (LMP1) car. It is a single-seat, carbon fiber monocoque car, purpose built for racing. It had originally $700 \mathrm{HP}$ when equipped with a V8 engine fueled by E85. The power was increased to $1100 \mathrm{HP}$ with the electric drivetrain. In its ICE version, it participated in the Le Mans $24 \mathrm{~h}$ race in 2010. In its EV version, it has set several FIA speed records and successfully participated in hill climb as well as other short duration events with its owner and driver Lord Paul Drayson. It has a top speed of $219.1 \mathrm{mph}(352.3 \mathrm{~km} / \mathrm{h})$.

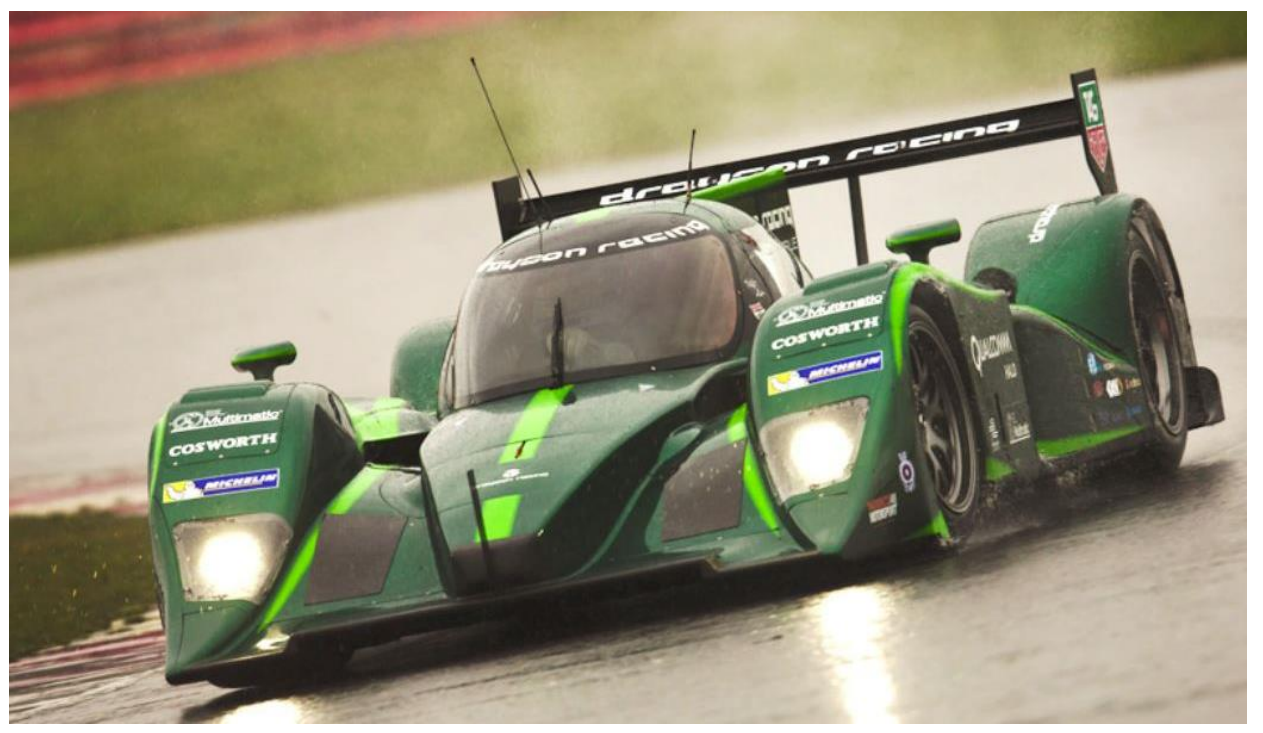

Figure 2: The Drayson B12/69EV, an example of an EV competitive with ICEs.

Photo courtesy of Drayson Racing Technologies.

The mass of the drivetrain, excluding battery/fuel tank, is lower in the EV version than it was in the ICE version. The combined mass of the motors, controllers, wiring and all other components except the battery of the $1100 \mathrm{HP}$ electric drivetrain is about $172 \mathrm{~kg}$. The mass of the original engine, transmission, and all other components except the fuel in the $700 \mathrm{HP}$ drivetrain was $302 \mathrm{~kg}$ [1]. Despite the electric drivetrain having an efficiency four times higher than the ICE drivetrain, the mass of the battery pack per unit energy is almost 100 times higher in the EV version: $11 \mathrm{~kg} / \mathrm{kWh}$ for the battery on a system level versus 0.12 $\mathrm{kg} / \mathrm{kWh}$ for E85.

The difference in specific energy can be improved by the selection of a higher specific energy battery type. However, unlike fuel, there is a significant tradeoff between power and energy. The battery pack in the Drayson B12/69EV was built for high power, safety, and reliability. This resulted in a relatively low specific energy. The car's duration per charge would be doubled if the specific energy of the battery pack was doubled, but this would result in a tradeoff in power and safety. This tradeoff would have made the car unsuitable for its intended purpose of setting lap and speed records. 
Figure 3 illustrates how the total mass of the drivetrain in a car like the Drayson B12/69EV would increase with required race duration. The mass of the $\mathrm{EV}$ drivetrain is scaled down to $700 \mathrm{HP}$ to be comparable with the ICE version. The dotted blue line represents an ICE drivetrain fueled with E85. The solid green line represents a drivetrain with a battery pack with $100 \mathrm{Wh} / \mathrm{kg}$ on the pack level, while the dotted green line represents a battery pack with twice the specific energy. Advances in battery technology will tilt the line more in favor of the EVs.

With the current available technology, we can conclude that an EV circuit racing car of this type can be competitive with ICE car, if the duration of the race does not exceed 6 to 13 minutes. This conclusion is purely based on the mass of the drivetrain. If other factors such as superior traction control and mass distribution, as well as the availability of full torque from zero, are taken into account, EVs can be competitive even if the mass is slightly higher than the ICE equivalent. Conversely, figure 3 assumes that all energy is used in the battery pack. In reality, some margin is needed. You should design your vehicle with the goal to have at least 10-20\% energy left in your battery pack at the end of the race.

Based on our own experience and these kinds of calculations, we have established the rule-of-thumb of $\sim 10$ minutes as the cut-off point where EVs currently can be competitive with ICEs. As the battery technology improves, this duration window will increase.

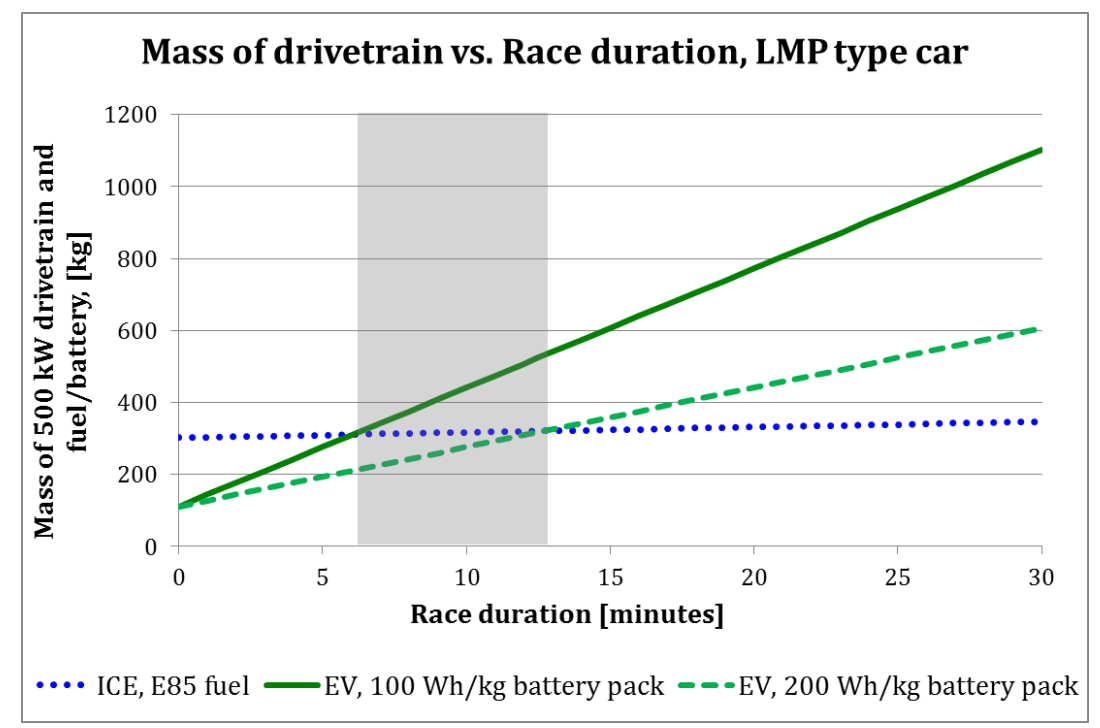

Figure 3: Mass of drivetrain including fuel/battery versus race duration for EVs and ICE of LMP type. Sources: [1-4]

\section{Selection of race discipline, format, and vehicle type}

\subsection{Race disciplines and formats}

There are quite a few options available for race disciplines and formats with a duration of about 10 minutes or less. Some of the most commonly known race disciplines that fit this requirement are the following:

- Hill climb

- Drag racing

- Land speed racing

- Track/sprint racing (<10 min)

- Rally cross

- Auto cross

- Monster truck

- Drifting
Specific for motorcycles:

- Trials

- Speedway/Flat track

Other types of vehicles:

- Snow mobile drag racing

- Airplane pylon races (<10 min)

Some of the suggested race formats may have heats longer than 10 minutes, but you will need to stay at or below 10 minutes to be competitive. It is also important to remember that racing in snow and sand consumes a lot of energy, and you might have to decrease the duration further to be competitive on these surfaces. 
It is obvious that NASCAR, Le Mans $24 \mathrm{~h}$, and endurance racing are not suitable race formats for EVs with the current available battery technology. Although these types of races can theoretically be finished through quick change of battery packs, the EV will not be competitive with ICE vehicles.

We should mention that there may be regulatory issues preventing EVs from participating in some of these race disciplines, but that is outside the scope of this paper. That is politics, not technology. In general, the more competitive you are, the better the chance that you will get to race. Racing is always show business, and racing organizers are typically quite generous if you give them a good show. You might have to begin by running exhibition, but when you have demonstrated that your vehicle is competitive, (or can "kick ass" as racers would express it), you are typically welcomed in.

\subsection{Vehicle type}

There can be many different reasons to choose a particular vehicle type. A common reason is the love of a specific kind of vehicle, such as motorcycles, cars, boats, or airplanes. No matter what your preference may be, or what vehicle suits your goals, there are some key criteria to keep in mind. The most important is that power is expensive. The motor(s), motor controller(s), and the battery pack(s) are often the most expensive parts of a racing vehicle. In contrast to other parts of the vehicle, such as the frame and bodywork, many of the drivetrain components such as battery cells, motor controllers, and high power motors requires highly specialized manufacturing equipment and are almost impossible to manufacture yourself. The second-hand market is also currently close to non-existent. However, the opportunity for sponsorship or discounts can be relatively good if you have an interesting project and good reputation.

To maximize the performance from the drivetrain you can afford, you want to have the smallest practical vehicle. Let's say that you can only afford a $400 \mathrm{HP}$ drivetrain, but want to set a speed record. In this case, you should consider putting that drive package in a motorcycle rather than in a truck, as that will give you a higher top speed. The cost of support equipment will also grow with the vehicle size, as does shipping costs and team size. In general, it is much less expensive to race a motorcycle than a car, something to keep in mind if you are on a tight budget.

\subsection{Sanctioning bodies and existing records}

If your goal is to set a record, you need to pay particular attention to the available sanctioning bodies. A sanctioning body is the organization that certifies and keeps track of the records. It is also the organization that establishes the class and safety rules. In many cases, but not all, they also organize the actual event. This means that there can be several different "official" records for the same vehicle class, registered by different sanctioning bodies. Confusing? Yes, absolutely, so pay careful attention or you can end up spending a lot of money and time without achieving your goal of an official record.

There are many forms of records, but some of the most commonly recognized records are land speed records. These are typically measured over a so called flying mile (or kilometer) where your average speed is measured over a mile (or kilometer). In the standing mile (or kilometer), your top speed is measured at the end of the mile (or kilometer). Another form of record is the $1 / 4$ mile (or 1/8 mile) records in drag racing, were both the time elapsed (E.T.) to reach the finishing line and your speed at the end of the $1 / 4$ mile (or $1 / 8$ mile) track are measured. The EV drag racing records are registered by the National Electric Drag Racing Association (NEDRA) in the United States. Records set in other countries can also be submitted to NEDRA. There are other organizations registering EV drag racing records, but NEDRA has the largest number of active racers. In case you plan for an EV drag racing vehicle, start by studying the existing records to see what your competition is and where there may be records easy to break. The drag racing records are categorized both by vehicle type and battery voltage. There are also special classes for student teams. You will notice that the top records are typically in the highest voltage classes. By choosing a slightly lower voltage class, you may find a record that that is much easier (and less expensive) to achieve.

Land speed racing have many more available sanctioning bodies than drag racing. One of the never ending debates within the land speed racing community is which records count as world records. We can only speak for ourselves, but there appears to be some general consensus that you can call a land speed record a world record only if it is sanctioned by Federation Internationale Motocyclisme (FIM) for motorcycles or Federation Internationale de l'Automobile (FIA) for cars. However, if you want to call your vehicle the world's fastest of a certain kind, your record has to exceed all other records - world records, international records, and national records - for this kind of vehicle. The KillaJoule is the world's fastest electric 
motorcycle with a national AMA (American Motorcyclist Association) record of $240.726 \mathrm{mph}(387.4 \mathrm{~km} / \mathrm{h}$ ) set in August 2014. Its official world record sanctioned by FIM is lower.

If your goal with your racing just says "land speed record", then you can, by careful choices, find a suitable class with a low or open record. An open record refers to a class where there are no previous records. This means that if you pass the technical inspection, comply with the class rules, and make two complete runs ${ }^{1}$, you will be the new record holder! That's cool, isn't it? An official record, no matter if it is national or international, always makes it easier to attract new sponsors (and keep your existing sponsors happy.)

\subsection{Make sure your vehicle actually fits in a class!}

It may sound surprising, but it is extremely easy to build a racing vehicle that won't fit in any competition class or record category. Your very first purchase (or download, if you are lucky) should be the rulebook for the racing discipline and sanctioning body that you are considering. Many organizations charge for the rule book, but at US\$ 10 or so, it is worth every penny. You won't be happy, and your sponsors certainly won't be happy, when you discover at the technical inspection that your vehicle doesn't pass the rules and you have to go home without having made a single run on the track. (It is surprizing how often this happens.)

\section{Resources and "business plan"}

Even if racing efforts rarely make money, or at least not directly, you do need a "business plan". The business plan will help you narrow down your options for racing disciplines, race formats, and vehicle types. You will also need it to help attract sponsors. Even if it initially may be written on the back of an old envelope, your business plan needs to include at least the following items:

- Passion/knowledge/expertise/team (what you already have).

- Overall goal (what you want to accomplish)

- Showcase a specific component?

- Personal goal, like beating somebody? Set a record?

- Be the first to do X?

- Budget and other resources, including existing or potential sponsors. (There is a limit to every budget, no matter how large of a team you have).

- Time frame (for example, certain races only go once a year).

All these items are at a similar level in the decision tree, and they have to be considered simultaneously. However, certain items such as budget and time frame may set firm limitations for your options. As much as we wish it wasn't the case, racing costs! And it can cost $a$ lot. There is no limit to how much that you can spend on a racing vehicle. Well, there is, and that is the over-draft limit of your checking account. In order to fulfill your electric racing dream, you have to aim for a goal that is in line with your budget. No point starting to build a 5,000 HP streamliner car with US\$1,000 in your budget. You won't even get a set of tires for that amount of money.

When you have decided how much you are willing to spend, at least double it. Our experience shows that racing effort will end up costing twice as much as you predicted, even if you take into consideration that it will be twice as expensive and you try to stay on budget. You can either set your budget and then cut it in half and decide that you are only allowed to spend half of it on your vehicle, or you can simply double your budget. It is purely your choice, but you should count on $100 \%$ contingency. This number may be higher if you budget is really low. Even if you can buy a US\$1,000 motorcycle on Craigslist and convert it using a fork lift motor and a starter battery, you will still need a truck and trailer, fuel, hotel, food, helmet, racing suit and a gazillion other things. Your US\$1,000 motorcycle will quickly turn into a US\$10,000 adventure if you don't watch your pennies very carefully. On the other hand, if you build a million dollar streamliner car, the cost of your transport vehicle, fuel, and accommodations may be "in the noise" so to speak.

Just to pick an example of unexpected expenses - the driver's personal racing gear. The requirements for personal safety equipment increase with your speed, and to some extent with the risk of certain vehicle types. Land speed racing vehicles typically have much higher safety gear requirements than drag racing. If you want to build a car to set a land speed record over $200 \mathrm{mph}$, count on spending an absolute minimum of US\$2,000 on your personal safety equipment alone (suit, helmet, boots, gloves, neck protector, fire

\footnotetext{
${ }^{1}$ There are a lot of technicalities surrounding records, so this statement is a bit simplified. Make sure to always read the rule book.
} 
extinguisher, etc.) The sum is similar for a motorcycle racer if you like a set of high-quality leathers and a lightweight helmet. For example, Eva's personal safety gear to ride the KillaJoule streamliner has cost more than twice that, and we have chosen far from the most expensive brands.

Junior Johnson said it best, "The way to make a small fortune in racing is to start with a large one." Electric racing is no different. It is still racing and is still expensive.

\subsection{Sponsorship}

We often say that finding sponsorship is like convincing your neighbor to buy you a big screen TV. Why on Earth would he do that?! You have to convince him that you have really cool friends, and if you have a big screen TV, your friends will come to your house, and your neighbor will be invited to the party as well and get to meet your cool friends. Your neighbour will immediately reply that he will buy the TV for himself, and your friends will come to his house instead. You have to politely explain to your neighbour that he isn't cool enough, and your friends will only come to your house. The situation with racing sponsors is very similar. Why would they pay you to build a race car, when they can just build themselves a race car. You have to convince them that you are much better at this, and that your race car will make sure their component or logo is seen by lots of important people.

It is fairly easy to make a case to an experienced sponsor if you compete in a well-known race series such as NASCAR. There are lots of statistics on the return in investment, and everybody knows about NASCAR. In electric racing, you have neither of these luxuries. Electric racing is still fairly unknown, and your potential sponsors will likely be "virgin". Companies that should have an interest in electric racing, such as a printed circuit board manufacturer, have typically never sponsored racing before. They don't understand the value of racing sponsorship to their business. They incorrectly assume that they will assume liability, etc. No market research or statistics on return on investment exists for electric racing. Many don't even understand how to go about sponsoring a team. Do we write a check? Create a contract? What should we tell our accountant?! It is easy to get "stuff", because it can just be registered as a free product sample in the accounting, but it is very difficult to get cash funds. The truth is that sponsorship agreements can be arranged in many different ways. It can be anything from a company (or person) sending you a check together with some vinyl stickers in an envelope, to elaborate high dollar endorsement deals with long negotiations.

Because of the difficulty in getting cash sponsorships, you are typically better off going for in-kind sponsorships as a new racing team. The cost of the components in an electric racing vehicle is not insignificant. In-kind sponsorships can also be things like machine shop time, which can be worth a lot.

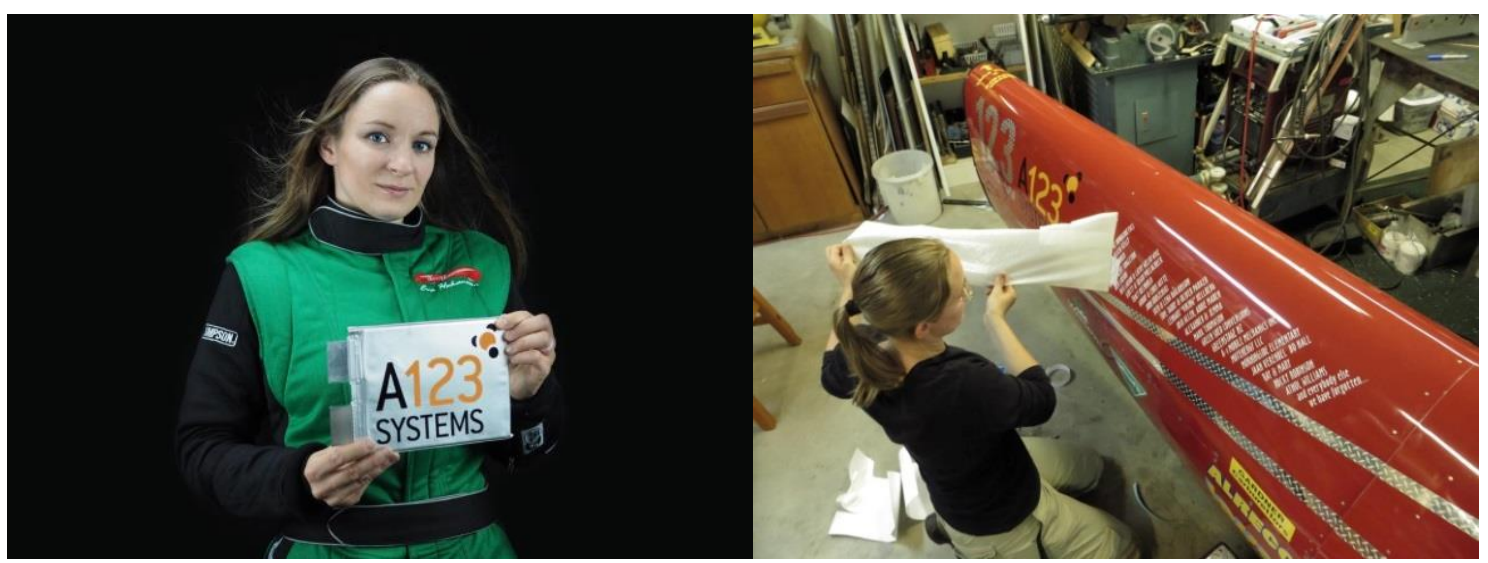

Figure 4: Left) Prominently displaying your sponsors is instrumental to a successful racing effort.

Right) A die-cut set of names like this can cost you several hundred US\$ when ordered from a local supplier. If you make them yourself using a cutting plotter, it will cost you a few dollars for the vinyl and a few hours of work.

\subsubsection{Make your own artwork}

What is a race car without artwork? It is just an ordinary car. A problem that we hadn't expected was the difficulty to get stickers with the sponsor logos. We had sponsors, but the sponsors had no vinyl stickers to put on the bike. In the few cases they had stickers, they were often either way too large or way too small for the contribution. One of our best investments was a computer controlled cutting plotter for vinyl film. We bought it online for US\$ 500, and we have used it to create almost all the artwork on the KillaJoule 
streamliner. It takes a couple of days work to create all the logos, names, and numbers for a typical racing vehicle; a job that a sign company would have charged thousands of dollars to perform. The access to a cutting plotter makes it easy to add new sponsors to the vehicle at any time.

\subsection{Publicity}

Unless you can afford to hire a PR person, you have to become your own PR machine. Eva takes care of all the PR for the KillaJoule team. She is apparently so successful that many people think that we a factory team with people on staff. They are shocked when they learn that the entire streamliner is built as a hobby project in our two-car garage behind our modest home, and that we both work regular day jobs.

\subsubsection{The secret to media coverage - offer free material}

If you thought you were poorly paid, you probably still make drastically more than the typical freelance writer. The budgets for even the largest magazines and newspapers are slashed, and to make a living as a writer you have to work really fast. This is something that you can take advantage of. All journalists are hurting for interesting stories that can be quickly put together. They also need photos, and having to pay for photos or send out a photographer doesn't result in a happy editor.

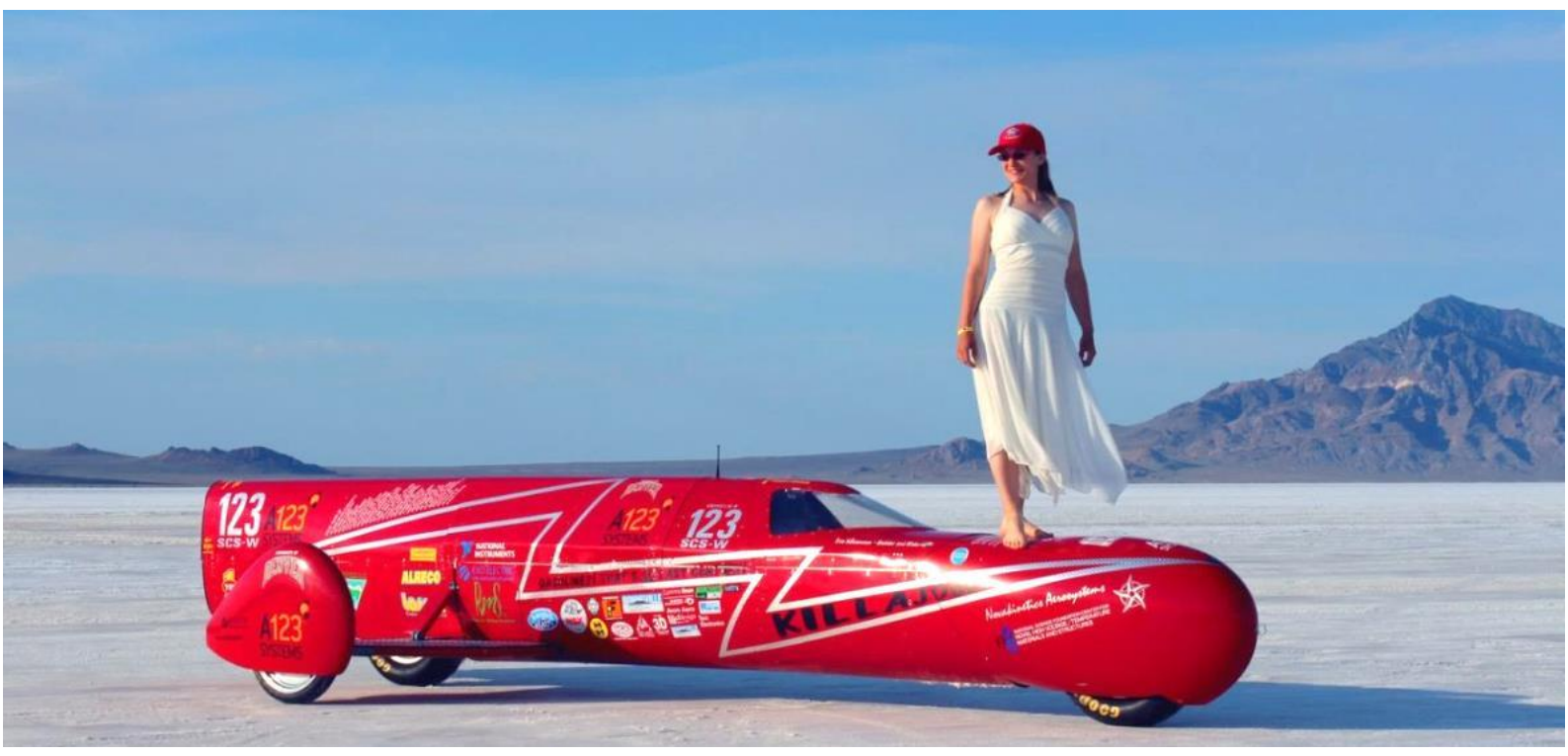

Figure 5: This was a completely spontaneous photo shoot wearing a dress that a spectator had brought to Bonneville. Eva didn't even have any suitable shoes, but it is one of the most published photos of the KillaJoule.

If you offer high-quality photos to the media for free, and if you write up your background story as well as short press releases (less than one page) when you set a record or do something else of media value, chances are very good that one or several writers will pick your story. The key is to do the work for the writer, like including facts and quotes that can be copied and pasted into an article. If you provide this, the likelihood of getting media coverage increases exponentially. At the bare minimum, you have to have a fact sheet with all the key records, specifications, and sponsor names listed. This is so members of the press will get the facts straight. Print a few copies of the fact sheet and bring it to the track. Don't forget to include contact information.

\section{Examples of successful battery powered racing vehicles}

There are several recent examples of racing EVs that are competitive head-to-head with ICEs. The Drayson B12/69EV mentioned above is one example. Last year's overall winner at Pike's Peak is another example. Two of our own electric racing motorcycles, the KillaCycle and the KillaJoule, also belong to this group.

Our own success in electric drag racing and land speed racing with countless world records has been possible through a careful selection of race formats and vehicle design. We found that drag racing and land speed racing offered the optimal combination of short duration, high power demand, and simple regulations. Both communities were welcoming to innovative approaches and open to create classes for EVs. We found it particularly easy to communicate results and records in land speed racing to sponsors and 
to the general public. High speeds always impress and we found it much easier to find sponsors in land speed racing than for any other racing discipline.

By adopting an approach where we primarily designed what we could build using our own relatively small machine shop in our two-car garage, we could keep the budget to a minimum. By choosing to build motorcycles instead of cars, we could get the maximum performance from the drivetrains that we could afford. It also kept support equipment such as the trailer small, and affordable.

\subsection{The KillaCycle - the world's quickest EV}

The KillaCycle is still the world's quickest electric vehicle at $0-60 \mathrm{mph}$ in less than 1 second. Its $1 / 4 \mathrm{mile}$ time of $7.62 \mathrm{sec} @ 169 \mathrm{mph}(272 \mathrm{~km} / \mathrm{h})$ was its best E.T. and its top speed record was $174 \mathrm{mph}$. It held the EV world record for the $1 / 4$ mile until just a few years ago.

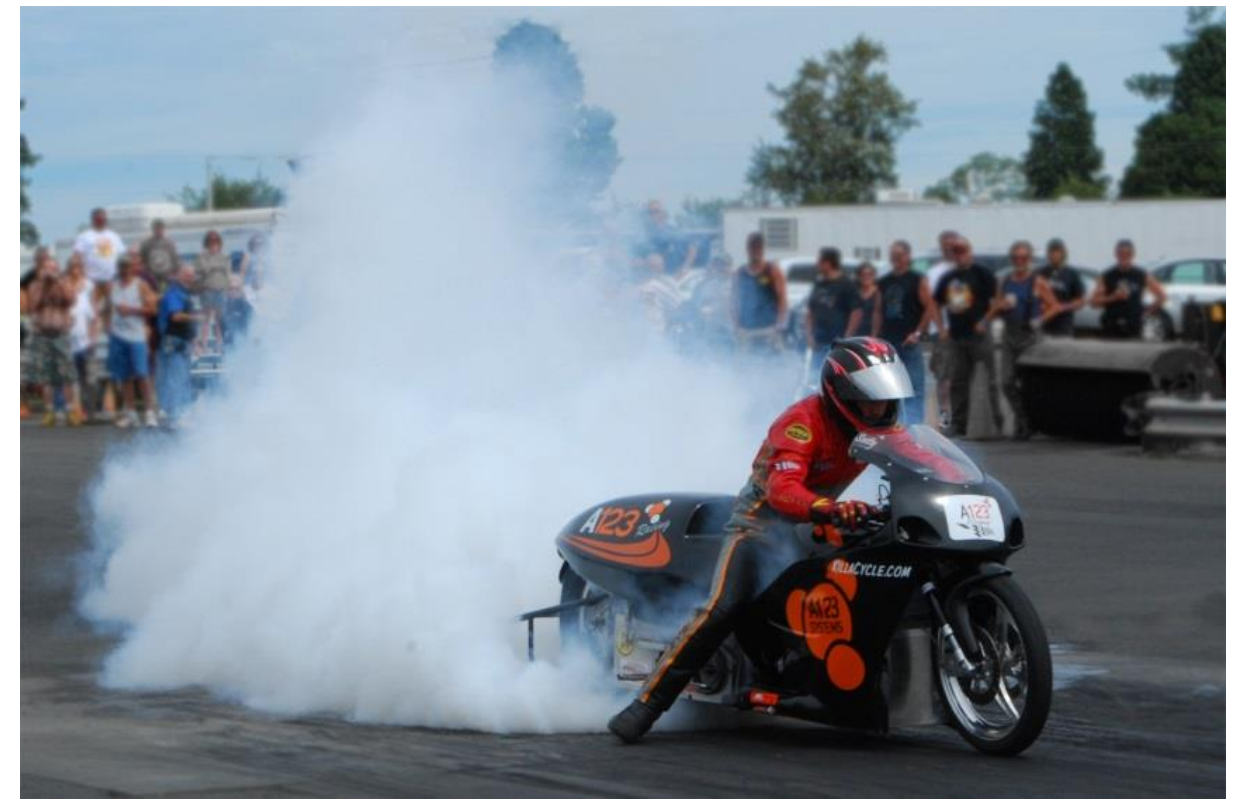

Figure 6: The KillaCycle with professional rider Scotty Pollacheck at Woodburn Raceway, Portland, Oregon, USA.

We have finally retired the KillaCycle after many years of racing and setting countless records (looking for a suitable museum for it now.) The KillaCycle was the first electric motorcycle to break the 10 second barrier in the $1 / 4$ mile, and then the 9 second barrier, then the 8 's, and then the first electric vehicle of any kind in the 7 's. It held the electric $1 / 4$ mile speed record for many years.

The original KillaCycle was built in 1999, and used state-of-the-art thin film lead-acid batteries. At the time, these batteries had the highest available power-to-weight-ratio, but the low specific energy did not allow for any other racing application than drag racing.

The KillaCycle was one of the first race vehicles to try Li-Ion batteries in 2003. We convinced A123 Systems to take a chance and to sponsor the KillaCycle with their high specific power, $\mathrm{LiFePO}_{4}$ cordless tool cells. It set a new world record during the first test session at the track, as we suspected it might. It was the breakthrough period for EV racing and for Li-Ion cells.

Table 1: KillaCycle technical data

\begin{tabular}{|c|c|}
\hline Current record: & The world's quickest electric motorcycle at $0-60 \mathrm{mph}$ in less than 1 second! \\
\hline Best E.T. and top speed: & Best E.T.: $7.62 \mathrm{sec} @ 169 \mathrm{mph}(272 \mathrm{~km} / \mathrm{h})$, Top speed: $174 \mathrm{mph}(280 \mathrm{~km} / \mathrm{h})$ \\
\hline Battery: & $\begin{array}{l}\text { A123 Systems Lithium Nano-Phosphate }{ }^{\mathrm{TM}}, 8 \mathrm{P} \text { 80S of } 18700 \text { "Formula 1" cells, } \\
264 \mathrm{~V}, 68 \mathrm{lb}(31 \mathrm{~kg}) \text {. }\end{array}$ \\
\hline Motors: & Two Advanced DC motors @ 87 lbs (40 kg) each \\
\hline Motor controllers: & Two Café Electric Zilla 2k-HV \\
\hline Total power: & Approximately $650 \mathrm{HP}$. \\
\hline Electricity consumption: & $0.6 \mathrm{kWh}$ per run, including the burn-out. \\
\hline Weight and dimensions: & Weight: $500 \mathrm{lb}(\sim 230 \mathrm{~kg})$, Wheelbase: $8 \mathrm{ft}(2.4 \mathrm{~m})$ \\
\hline Owner, designer, and builder: & Scotty Pollacheck and Tracy Helmhold \\
\hline
\end{tabular}




\subsection{The KillaJoule - the world's fastest sidecar motorcycle}

The KillaJoule is the world's fastest electric motorcycle, but also the world's fastest sidecar motorcycle with an official record of $240.726 \mathrm{mph}(387 \mathrm{~km} / \mathrm{h})$ and a registered top speed of $270.224 \mathrm{mph}(434 \mathrm{~km} / \mathrm{h})$. The KillaJoule has bested all ICE sidecar motorcycle land speed records by a large margin. This is the first time in over a century that a battery powered vehicle has taken the overall record for a vehicle type. In 1899 the world's fastest car was battery powered, since then ICEs have completely dominated racing, until now. If we also include the two-wheelers, less than 10 motorcycles in the world are faster than the KillaJoule. It is just a matter of time (and money) before an electric motorcycle takes the overall speed record. The top speed of over $270 \mathrm{mph}$ also made Eva the world's fastest female motorcycle rider.

The decision to build a motorcycle rather than a car was based on the smaller frontal area, the lower component cost, and the less complex design. In the international land speed racing rules, a car is defined as vehicle with four or more wheels, while a motorcycle is defined as a vehicle with two or three wheels. A sidecar motorcycle is defined as a vehicle that has two wheels in line, and one wheel offset. The sidecar motorcycle streamliner configuration offered the smallest possible frontal area, but would at the same time provide similar stability and safety of a car. With only one steering wheel and one driving wheel, the complexity of the chassis was drastically reduced compared a car. The simple design allowed the KillaJoule to be built on a minimal budget in our two-car garage. The results have shown that this was a successful strategy. At a "merely" $400 \mathrm{HP}$ and a combined budget of around US\$ 250,000 (of which about half is inkind sponsorships), the KillaJoule is the world's $3^{\mathrm{rd}}$ fastest battery powered EV. Only the multi-million dollar efforts of the Buckeye Bullet 1 and 2.5 from Ohio State University have achieved higher speeds.

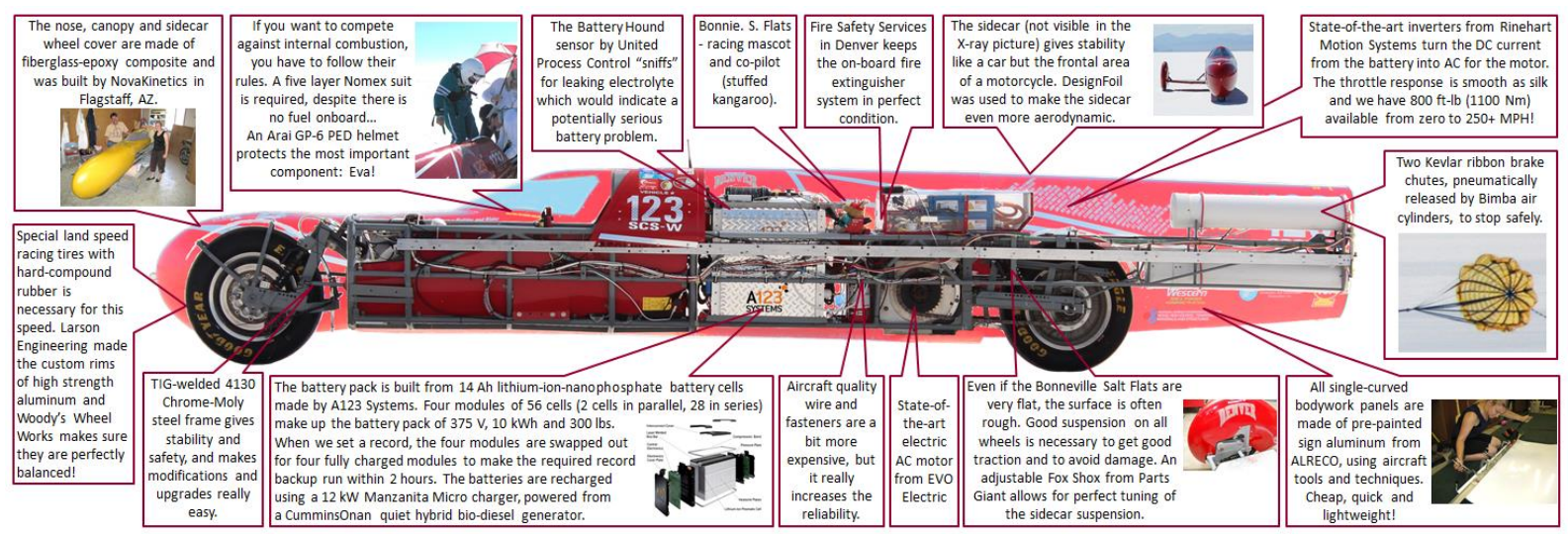

Figure 7: The KillaJoule.

About $80 \%$ of KillaJoule was fabricated by Eva, the rest by family and friends. Working on evenings and weekends alone, it took 18 months from the start of the build to the first world speed record. The KillaJoule is now 6 years old, and has continuously been upgraded for higher power and higher speed. The current drivetrain with battery cells from A123 Systems, motor from GKN/Evo Electric, and motor controllers from Rinehart Motion Systems is capable of approximately $400 \mathrm{HP}$.

The 2015 racing season completely rained out at Bonneville Salt Flats. If the Bonneville Salt Flats dries up normally this year and gives us a decent track to race on, and the planets align, we are hoping to break 300 mph this fall with the KillaJoule.

Table 2: KillaJoule technical data

\begin{tabular}{|c|c|c|c|c|c|}
\hline Current record: & \multicolumn{5}{|c|}{$\begin{array}{l}\text { The world's fastest electric motorcycle and the world's fastest sidecar motorcycle @ 240.726 MPH } \\
(387.4 \mathrm{~km} / \mathrm{h}) \text {. Guinness World Record for "fastest 3-wheeled streamlined electric motorcycle" }\end{array}$} \\
\hline Top s & \multicolumn{5}{|c|}{$270.224 \mathrm{mph}(434.9 \mathrm{~km} / \mathrm{h})$ at Mike Cook's Land Speed ShootOut, Bonneville Salt Flats, USA } \\
\hline Battery: & \multicolumn{5}{|c|}{$\begin{array}{l}\text { A123 Systems Lithium Nano-Phosphate }{ }^{\mathrm{TM}}, 14 \text { Ah pouch cells in a } 2 \mathrm{P}-112 \mathrm{~S} \text { configuration, } 10 \\
\mathrm{kWh}, 375 \mathrm{~V} \text {, approximately } 300 \mathrm{lbs}(135 \mathrm{~kg})\end{array}$} \\
\hline Motor: & \multicolumn{5}{|c|}{ EVO Electric AFM-240 } \\
\hline Motor controllers: & Two Rinehart Motio & Systems PM100 & & tal power: & Approximately $400 \mathrm{HP}$ \\
\hline $\begin{array}{l}\text { Weight and } \\
\text { dimensions: }\end{array}$ & \multicolumn{5}{|c|}{$\begin{array}{l}\text { Weight: } 1450 \mathrm{lbs}(660 \mathrm{~kg}) \text {. Dimensions: Length } 19 \mathrm{ft}(5.6 \mathrm{~m}) \text {, width: } 21 \text { inches }(0.53 \mathrm{~m}) \text {, height: } 38 \\
\text { inches }(0.96 \mathrm{~m}) \text {, wheelbase } 150 \text { inches }(3.8 \mathrm{~m}) \text {, track with sidecar } 45 \text { inches }(1.14 \mathrm{~m})\end{array}$} \\
\hline Rider and builder: & Eva Håkansson & \multicolumn{2}{|c|}{ Crew chief and builder: } & \multicolumn{2}{|l|}{ Bill Dubé } \\
\hline \multicolumn{2}{|c|}{ Senior advisor and suspension designer: } & Sven Håkansson & Crew: & \multicolumn{2}{|c|}{ Mike Stockert, Alicia Kelly \& Kent Singleton. } \\
\hline
\end{tabular}




\subsection{EVs dominate at Pike's Peak Hill Climb}

2015 was a ground breaking year in the almost 100 year history of the legendary Pike's Peak International Hill Climb race. Rhys Millen took the overall victory in the Drive eO PP03 electric car with a staggering time of 9 minutes 7.222 seconds, followed by Nobuhiro "Monster" Tajima in the his Rimac-engineered ERunner Concept_One at 9 minutes 32.401 seconds [5]. Never before had an EV taken the overall victory.

Tim Eckert is an electric pioneer at Pike's Peak driving his Li-Ion powered ER2 up the mountain in 2002 setting the bar for EVs. In 2003, the ER3, built by Tim and driven by Jeri Unser pared the electric record down to 14 minutes. The electric record has steadily been going down as batteries improve and frankly as $\mathrm{EV}$ race team budgets have gone up to the current point where electric is neck and neck with internal combustion.

These results confirm that hill climb is one of the most suitable race disciplines for EVs. The duration of a typical hill climb race is typically of the order of a few minutes. The Pike's Peak race, with the top competitors finishing in around 9 minutes, is one of the longest hill climb races in the world, but still within the perfect range for EVs. The Pike's Peak Hill Climb also has other features that cater to EVs. The 12.42 mile $(19.99 \mathrm{~km})$ course starts at 9,390 ft. $(2,862 \mathrm{~m})$ elevation and finishes at $14,115 \mathrm{ft}$. $(4,300 \mathrm{~m})$ [5]. Towards the end of the 4,720 ft. $(1,440 \mathrm{~m}) \mathrm{climb}$, the ICEs have lost up to $30 \%$ of their power due to the thin air [5], while the EVs are essentially unaffected.

The four wheel independent regenerative braking possible in EVs along with near instantaneous traction control and four wheel independent drive provide an insurmountable advantage in handling and traction. EV's are very much at home on the twisty 156 turn Pike's Peak course.

The insane power emanating from the current state-of-art motors, controllers, and batteries was also reflected in the 2015 top contenders. The winner Drive eO PP03 has a reported 1368 HP [6] with a curb weight of $1150 \mathrm{~kg}$ [7], while the runner-up Tajima Rimac E-Runner Concept_One has a staggering 1496 HP with a curb weight of $1500 \mathrm{~kg}$ [8].

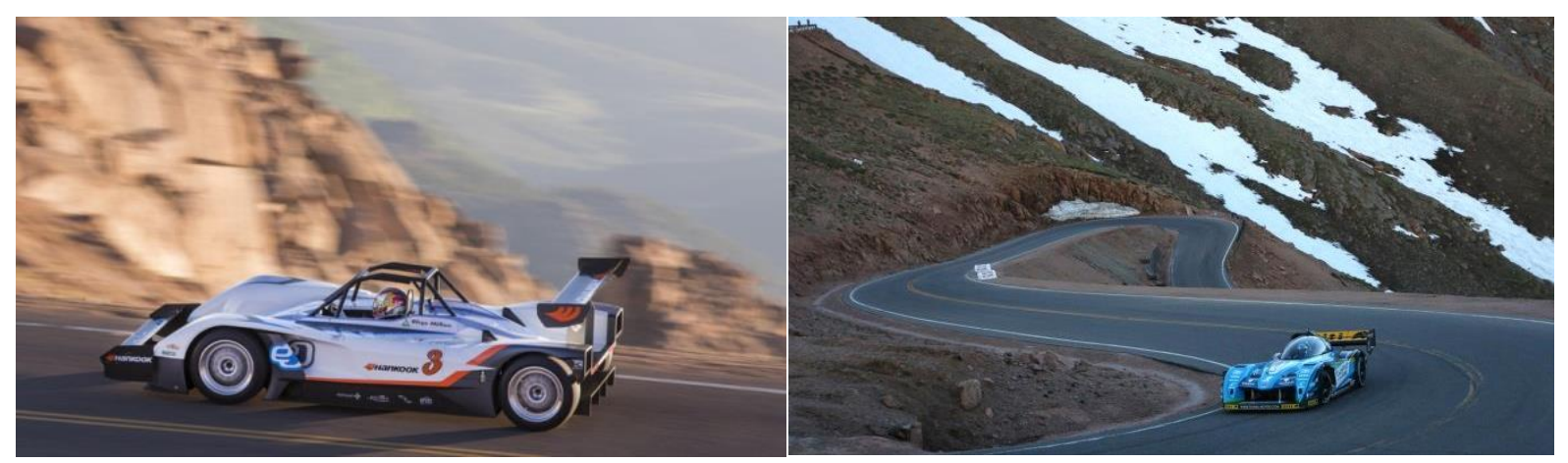

Figure 8: Left) The overall winner of the 2015 Pike's Peak International Hill Climb Rhys Millen with the Drive eO PP03. Right) The runner-up Nobuhiro "Monster" Tajima with the Tajima Rimac E-Runner Concept_One. Photo courtesy of Alastair Ritchie/Red Bull Content Pool and Team APEV.

\section{Conclusions}

EVs are already a game changer in certain racing disciplines such as hill climb and land speed racing, which both offer short race formats perfect for EVs. It is just a matter of time before overall records will be set by EVs. EVs can also be competitive in other disciplines if the vehicle type and race format are chosen wisely. For those of you that want to enter the world of electric racing, now is the time to act. The technology is here to be competitive, the battery technology is being continuously improved, and sponsors are beginning to become aware of the competitiveness of EVs. However, most of the current race teams have not discovered the advantages of EVs, and few teams have the experience and knowledge necessary to build a competitive electric vehicle. If you already have the background in electric vehicles, you can relatively quickly learn what you need to know about racing, and you will have a huge advantage compared to other racing teams.

The introduction of EVs in racing also brings in new potential sponsors that would never consider traditional racing. However, attracting sponsors is always very difficult, and you will need a clear "business plan" as well as reasonable goals to attract and - perhaps even more importantly - to keep sponsors. We prefer to under-promise and over-deliver, which has been a successful strategy for us. You also need a 
publicity strategy. It doesn't need to involve a large PR team, but you need to provide free material to the press such as photos, fact sheets, and press releases. Publicity is what attracts sponsorship.

While EVs can be highly superior to ICEs in power, acceleration, handling, traction control, and reliability, it is important to not "over innovate" in electric racing and lose that vital reliability edge. It is always tempting to be "Oh so clever" but you are far better off building a traditional vehicle that only changes the components that are to your competitive advantage to change. We always say "To finish first, one must first finish".

\section{More resources}

More about the authors: www.HakanssonDube.com and www.EvaHakanssonRacing.com

Drayson Racing Technologies: www.draysontechnologies.com

National Electric Drag Racing Association: www.NEDRA.com

Bonneville Motorcycle Speed Trials: www.bonnevillespeedtrials.com

Southern California Racing Association (sanctions land speed racing): www.scta-bni.org

\section{Acknowledgments}

We want to thank Oliver Jones at Drayson Racing Technologies and Mate Rimac at Rimac Automobili for providing data and information. We also want to thank all ours sponsors that have made our own racing effort possible, and in particular A123 Systems, Rinehart Motion Systems, EVO Electric/GKN, Manzanita Micro, NovaKinetics Aerosystems, Larson Engineering, Cummins Onan, National Instruments, Woody's Wheel Works, Arai, and our newest sponsor Parts Giant. We also owe a big "thank you" to our awesome volunteer crew Mike Stockert, Alicia Kelly, and Kent Singleton.

\section{References}

1. Jones, O., Drayson Racing Technologies. 2016.

2. $\quad$ Department-of-Energy, Alternative Fuels Data Center: Fuel Properties Comparison 2014: http://www.afdc.energy.gov/fuels/fuel_comparison_chart.pdf.

3. RacingSportsCars.com. Le Mans 24 hours, results 2010. 2010 [cited 2016 March 13]; Available from: http://www.racingsportscars.com/photo/Le_Mans-2010-06-13.html.

4. Lefebure, R., Lola-Judd B10/60 LMP1 Coupé, in The Sunday Times. 2010.

5. PPIHC. Pike's Peak International Hill Climb. 2015 [cited 2016 March 17]; Available from: http://www.ppihc.com.

6. Wright, E. On-Board with Rhys Millen Winning Pikes Peak 2015. Redbull.com, 2015.

7. Lopez, J. 2015 Drive eO PP03 Topspeed.com, 2015.

8. APEV. 2015 Tajima Rimac E-Runner Concept_One. 2015 [cited 2016 March, 17]; Available from: http://www.apev.jp/teamapev/2015/team_e.html.

\section{Authors}

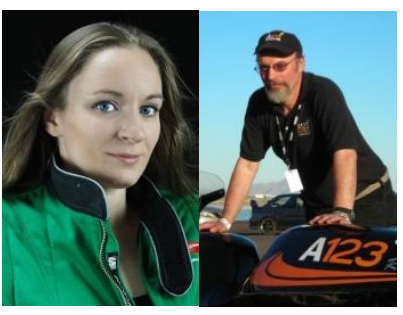

Eva Håkansson and Bill Dubé are the power couple of electric racing. This wifehusband team has countless of world records in land speed racing and in dragracing with their electric motorcycles. They are both mechanical engineers and have together over 25 years of experience from electric racing and high-performance electric vehicles. Eva is currently the world's fastest female motorcycle rider. She is also the principal builder of her record-setting sidecar streamliner motorcycle the KillaJoule. 